\title{
Compliance of education journals in Vietnam with the minimum criteria to be indexed in the ASEAN Citation Index and Scopus
}

\author{
Trung Tran', Loc Thi My Nguyen², Thanh Thi Nghiem², Hien Thi Thu Le², \\ Cuong Huu Nguyen ${ }^{2}$, Thuy Phuong La ${ }^{2}$, Trung Tien Nguyen ${ }^{3}$, Hang Thi-Thu Nguyen ${ }^{4}$ \\ 'Vietnam Academy for Ethnic Minorities, Hanoi; ${ }^{2}$ University of Education, Vietnam National University Hanoi, Hanoi; ${ }^{3}$ Vietnam \\ Journal of Education, Hanoi; ${ }^{4}$ Thai Nguyen University of Agriculture and Forestry, Thai Nguyen, Vietnam
}

Abstract

This study aimed at elucidating the present situation of scholarly journals published in Vietnam according to the minimum criteria to be indexed in the ASEAN Citation Index (ACI) and Scopus, with the goal of suggesting development strategies for scholarly journals in Vietnam. From the 387 journals accredited by the Vietnamese State Council for Professorship, 13 education journals were arbitrarily selected, and their compliance with the five minimum criteria for the ACI (peer review, timeliness, abstracts in English, references in Roman script, and a website in English) and the six minimum criteria for Scopus (peer review, timeline, abstracts in English, references in Roman characters, Electronic International Standard Serial Number [ISSN], and publication ethics) were assessed. Two of the 13 journals were eligible to be indexed in the ACI, while none fulfilled the minimum criteria to be indexed in Scopus. An urgent task for the editors of those journals is to establish an informative journal homepage in English that provides basic information on the journal. Then, an Electronic ISSN can be obtained from the ISSN International Center. Furthermore, the following steps are suggested for journal promotion: establishment of appropriate editorial policies and publication ethics procedures, improvement of research integrity, enhancement of the journals' reputation in the international scientific community, and improvement of the online publishing system by adopting a journal manuscript management system. To achieve those goals, financial support from the Vietnamese government will be invaluable.

Keywords

Editorial policies; Vietnam; Peer review; Publications; Financial support 


\section{Introduction}

The improvement of scholarly journals published in Vietnam to meet international publication standards is in accordance with the Vietnamese government's guidelines and policies towards the development of scientific and technological capacities of higher education institutions. Furthermore, it is associated with trends in the promotion of the Vietnamese higher education system to the international level. However, despite efforts by the Vietnamese government and higher education institutions to improve the quality and quantity of scholarly journals, the status of journal publishing in Vietnam still remains under expectations. As of August 2018, there were 387 journals approved for inclusion in the list of accredited scholarly journals for consideration in promotion decisions for professors [1]. Only six of those journals (1.6\%) were indexed in Scopus and/or the Emerging Sources Citation Index, including Vietnam Journal of Mathematics, Acta Mathematica Vietnamica, Advances in Natural Sciences: Nanoscience and Nanotechnology, Advanced Materials and Devices Journal, Biomedical Research and Therapy, and Progress in Stem Cell. As of June 2019, only 12 of the 387 (3.1\%) Vietnamese accredited scholarly journals were indexed in the ASEAN Citation Index (ACI), as presented in Suppl. 1 [2]. Moreover, Vietnamese scholarly journals also face the following challenges in submission, editing, reviewing, and publishing: competition to recruit high-quality papers, finding international reviewers, low journal reputation (not indexed in Web of Science and/or Scopus), the need to reach a wider and larger readership, and meeting international standards for scholarly journal publications. This situation is quite similar to those of other ASEAN countries, such as the Philippines, as reported by TecsonMendoza in 2015 [3].

To find strategies for promoting scholarly journals in Vietnam to the international level, this study aimed to elucidate the status of scholarly journals in Vietnam. Of the 387 journals accredited by the Vietnamese State Council for Professorship, 13 education journals were arbitrarily selected. Those journals' websites and print versions were searched in order to determine whether they met the minimum selection criteria of the ACI and Scopus. According to the results, we would like to suggest long-term strategic solutions to improve scholarly journals in Vietnam, both in the education category and in other fields.

\section{What is the $\mathrm{ACl}$ ?}

According to the ACI Steering Committee [4], the new initiative of developing a central regional citation database was proposed at the fourth Meeting of Directors-General, Secre-
tary-General, Commissioner of Higher Education in Southeast Asia held in Jakarta, Indonesia in March 2010. The meeting stressed the importance of regional collaboration in establishing the ACI as a database to enhance research in Association of South East Asian Nations (ASEAN) countries and to increase the visibility of ASEAN research productivity [5].

Inspired by the Web of Science and/or Scopus, the mission of ACI is to become "a central regional database which was designed and set up to index all the bibliographic records and the citations of all quality ASEAN research outputs appeared in the ASEAN scholarly journals." The ACI's member countries include Brunei, Cambodia, Indonesia, Laos, Malaysia, Myanmar, the Philippines, Singapore, Thailand, and Vietnam. The ACI Steering Committee consists of 20 experts nominated by member countries to establish policies and oversee the implementation and development of ACI. The ACI Steering Committee conducts annual meetings to share experiences, monitor implementation, and evaluate and approve journals to be indexed in the ACI database. As of the end of June 2019, the ACI database consisted of a total of 587 scientific journals from countries in the ASEAN region [2]. To be indexed in the $\mathrm{ACI}$, scientific journals published in the 10 ASEAN member countries must undergo a rigorous appraisal process according to the selection criteria developed by the ACI Steering Committee, including five pre-selection criteria and nine selection criteria [6].

\section{Compliance of Education Journals in Vietnam with the Five Pre-selection Criteria of the ACI}

The keyword "education" was used to search 387 journals accredited by the Vietnamese State Council for Professorship. There were 13 journals that had the keyword "education" in their name (Table 1).

The content of the journal website and print version was searched. The five pre-selection criteria of the ACI are as follows [6,7]: peer review, timeliness of publication, abstracts in English, references in Roman script, and journal website in English. Two of the 13 selected education journals were eligible to be indexed in the ACI database (Table 2). Two journals had a journal homepage in English. For the other journals, it was difficult to verify the items for evaluation via their online resources only.

\section{Compliance of Education Journals in Vietnam with the Minimum Criteria to be Indexed in Scopus}

According to the journal selection policy of Scopus [8], journal titles should meet all of the following minimum criteria to be considered for review: 1) consist of peer-reviewed content 
Table 1. List of 13 education journals accredited by the Vietnamese State Council for Professorship (2018)

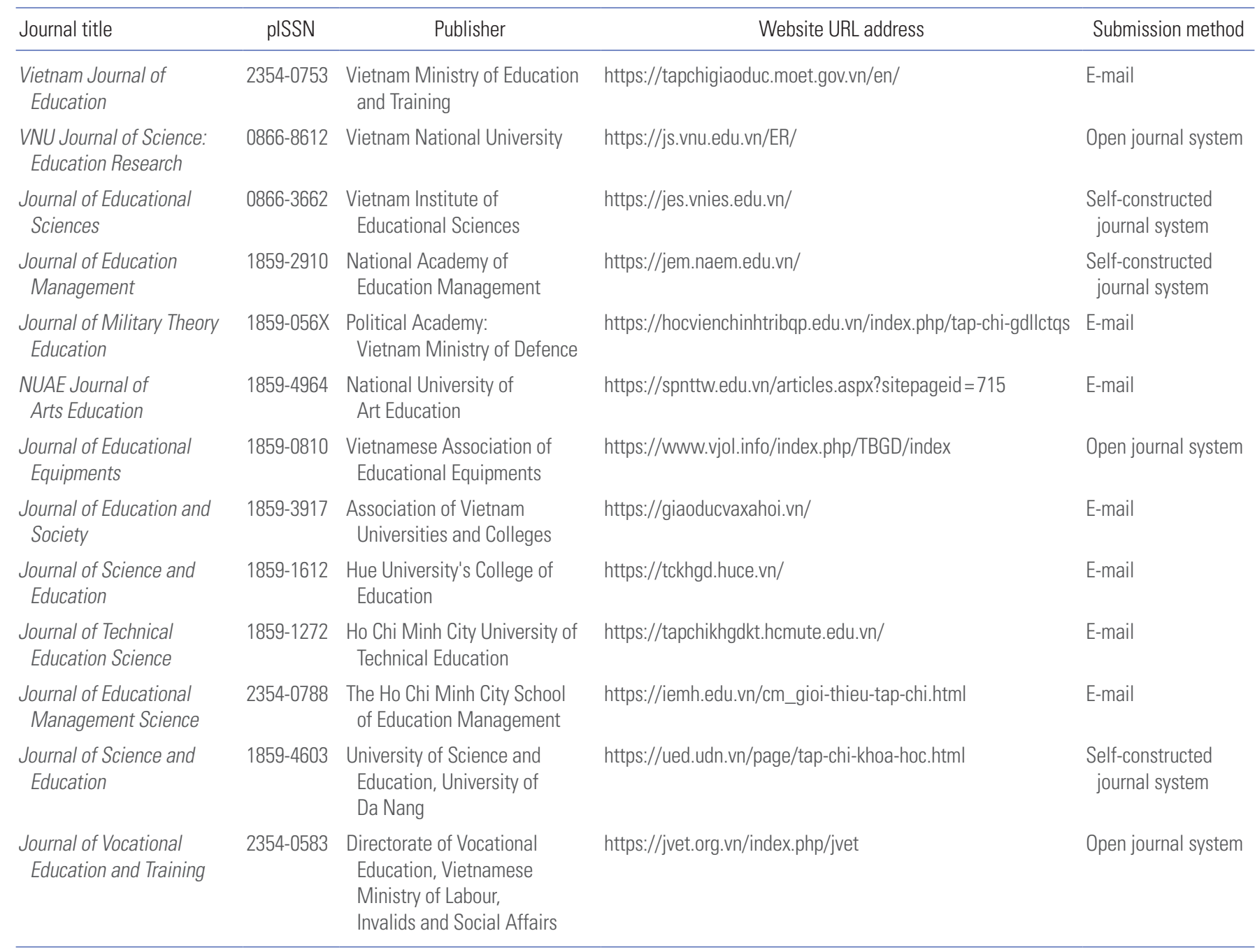

pISSN, print International Standard Serial Number.

and have a publicly available description of the peer review process; 2) be published on a regular basis and have an International Standard Serial Number (ISSN) as registered with the ISSN International Centre; 3) have content that is relevant for and readable by an international audience, meaning: have references in Roman script and have English language abstracts and titles; and 4) have a publicly available publication ethics and publication malpractice statement.

The results of the analysis of the 13 journals is summarized in Table 3. None of the 13 journals fulfilled the minimum selection criteria to be considered for review and evaluation for Scopus inclusion. One journal had an eISSN that could be confirmed through the ISSN portal (https://portal.issn.org). One journal mentioned publication ethics on the journal homepage. No journals provided a full statement about publication ethics and a statement about the use of anti-plagiarism software systems.

\section{What Should Vietnamese Editors Do to Promote Their Journals to the International Level?}

The above-described situation of the 13 journals reveals that they should take steps to the reach the minimum standards of scholarly journals. To fulfil the minimum standards listed in the ACI and Scopus selection process, there should be an informative journal homepage in English that provides the journal title, publisher, aims and scope, editorial board, instructions for authors, publication ethics, contact address, archiving sites, and full-text content of articles including the title, year, volume, page, authors' names, and authors' affiliations. After constructing a journal homepage in English with an independent domain, the editor or publisher should obtain an eISSN from the ISSN International Center through the National Library of Vietnam. Although this is a difficult and 
Table 2. Compliance of 13 education journals in Vietnam with the minimum criteria of the ASEAN Citation Index

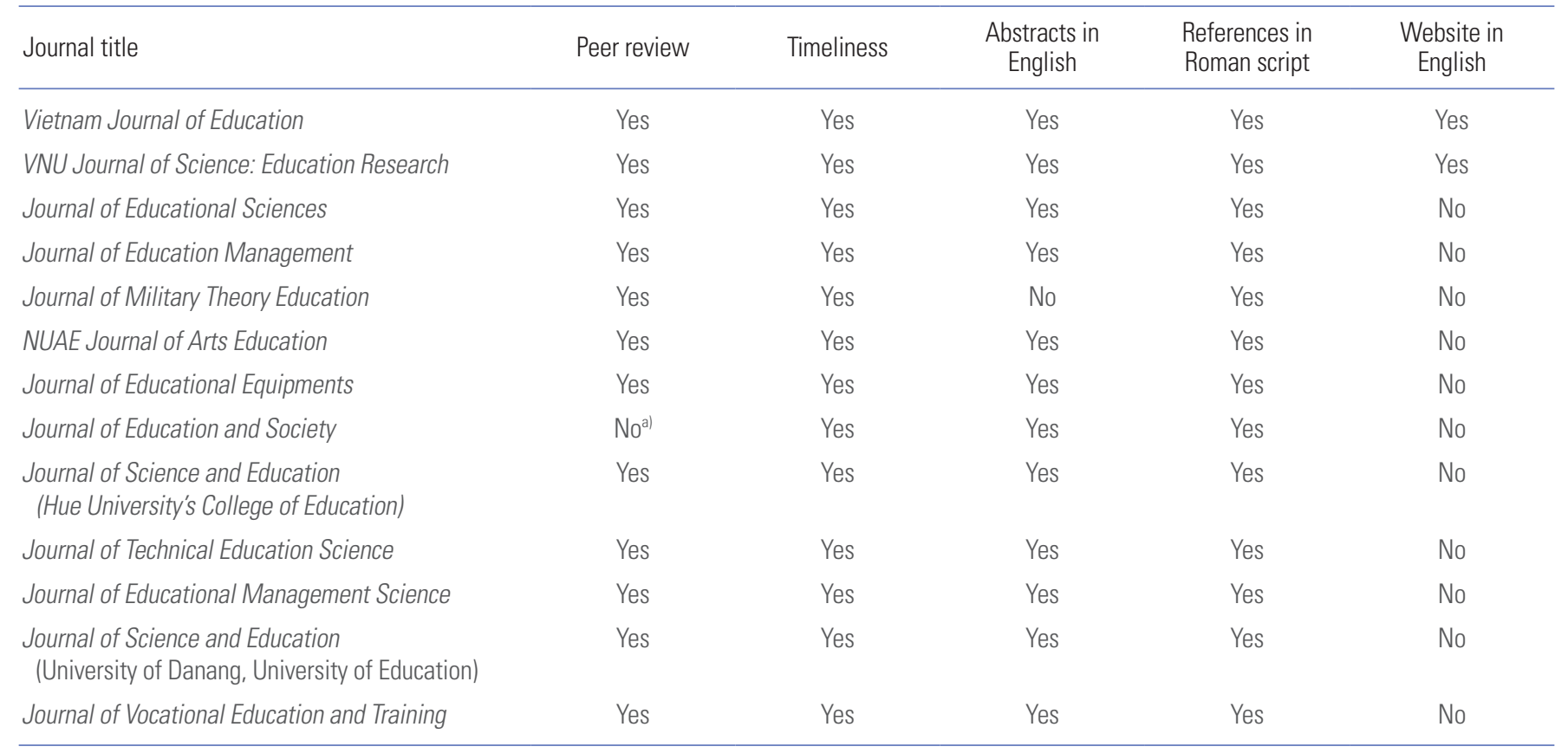

a) Some of the manuscripts are reviewed by the editorial board.

Table 3. Compliance of 13 education journals in Vietnam with the minimal criteria to be indexed in Scopus

\begin{tabular}{|c|c|c|c|c|c|c|}
\hline Journal title & $\begin{array}{l}\text { Peer-review } \\
\text { description }\end{array}$ & Timeline & elSSN & $\begin{array}{l}\text { Title and abstract } \\
\text { in English }\end{array}$ & $\begin{array}{l}\text { Reference in } \\
\text { Roman characters }\end{array}$ & $\begin{array}{l}\text { Publication } \\
\text { ethics }\end{array}$ \\
\hline Vietnam Journal of Education & Yes & Yes & No & Yes & Yes & $\mathrm{No}^{\mathrm{bl}}$ \\
\hline Journal of Educational Sciences & Yes & Yes & No & Yes & Yes & $\mathrm{No}^{\mathrm{bl}}$ \\
\hline Journal of Education Management & Yes & Yes & No & Yes & Yes & $\mathrm{No}^{\mathrm{b})}$ \\
\hline NUAE Journal of Arts Education & Yes & Yes & No & Yes & Yes & $\mathrm{No}^{\mathrm{b})}$ \\
\hline Journal of Educational Equipments & Yes & Yes & No & Yes & Yes & $\mathrm{No}^{\mathrm{bl}}$ \\
\hline Journal of Education and Society & $\mathrm{No}^{\mathrm{al}}$ & Yes & No & Yes & Yes & $\mathrm{No}{ }^{\mathrm{bl}}$ \\
\hline Journal of Science and Education & Yes & Yes & No & Yes & Yes & $\mathrm{No}^{\mathrm{bl}}$ \\
\hline \multicolumn{7}{|l|}{ (Hue University's College of Education) } \\
\hline $\begin{array}{l}\text { Journal of Science and Education } \\
\text { (The University of Danang, University of Education) }\end{array}$ & Yes & Yes & No & Yes & Yes & $\mathrm{No}^{\mathrm{bl}}$ \\
\hline Journal of Vocational Education and Training & Yes & Yes & No & Yes & Yes & $\mathrm{No}^{\mathrm{bl}}$ \\
\hline
\end{tabular}

eISSN, electronic International Standard Serial Number.

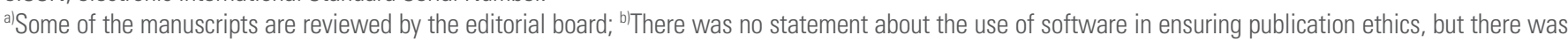
a statement of compliance with publication ethics in the printed version or on the website.

challenging process that requires long-term and persistent efforts and appropriate investment in financial and human re- sources, journal editors should have a long-term strategy for improvement. 
Table 4. List of non-commercial open source publishing platforms

\begin{tabular}{lll}
\hline System & \multicolumn{1}{c}{ Provider } & \multicolumn{1}{c}{ Website } \\
\hline Open Journal System & Public Knowledge Foundation & https://pkp.sfu.ca/ojs/ \\
DPubS & Cornell University Library, USA & http://dpubs.org \\
Digital Commons & Bepress & https://www.bepress.com/products/digital-commons/features/journal-publishing/ \\
\hline
\end{tabular}

The following specific solutions are suggested. First, the journals' editorial policies and publication ethics should be established according to international standards in terms of the style and format of manuscripts, editorial policy, review process, and publication ethics policies. A more efficient way to describe the above items is that journals should follow the "principles of transparency and best practice in scholarly publishing, third version" [9]. These principles will also help editors to ensure that appropriate processes are in place to deal with any kinds of publication misconduct.

Second, the research integrity of articles should be improved. One method to maintain research integrity is to use plagiarism detection software.

Third, steps should be taken to enhance the journals' reputation in the international scientific community. More specifically, the journals need to be developed from locally recognized journals to internationally recognized journals by establishing partnerships with experts and editors from other countries.

Fourth, online publishing should be improved by adopting a manuscript management system to receive submissions and to manage manuscripts during the review process. Taking into consideration the current financial capacity of scholarly journals in Vietnam, a feasible solution would be to use one of the open-source platforms for manuscript submission and publishing listed in Table 4.

\section{Conclusion}

To elucidate the present situation of scholarly journals in Vietnam, 13 education journals were selected for their eligibility to be indexed in the ACI and Scopus. Two of them were eligible to be indexed in the ACI, while none of them fulfilled the minimum criteria for both databases. Promotion of those journals to the international level, at which they would be eligible to be indexed in international literature databases, is an urgent task for the journal editors. Given the rapid economic developments and scientific achievements in Vietnam, there is the possibility that scholarly journals in Vietnam will be able to reach the level of first-rate international journals in the near future. To hasten this process, it is suggested that the Vietnamese government and other stakeholders should im- plement priority-based policy interventions and provide financial support to help scholarly journals in Vietnam to achieve internationalization.

Vietnamese journal editors should pay more attention to constructing journal homepages in English with independent domains, building or using manuscript management systems, and using tools to detect plagiarism to maintain publication ethics more efficiently.

\section{Conflict of Interest}

No potential conflict of interest relevant to this article was reported.

\section{Supplementary Material}

Supplementary file is available from the Harvard Dataverse at: https://doi.org/10.7910/DVN/B0A68W.

Suppl. 1. List of 12 journals indexed in the ASEAN Citation Index, out of the 387 Vietnamese accredited scholarly journals.

\section{References}

1. Tran VN. Improving the quality of Vietnamese scientific journals to meet the requirement of international integration. Hanoi: Vietnamese State Council for Professorship; 2018.

2. ACI Steering Committee. List of ACI journals [Internet]. [place unknown]: ACI Steering Committee; 2019 [cited 2019 Jun 20]. Available from: http://www.asean-cites.org/ index.php? $r=$ contents\%2Findex\&id $=9$

3. Tecson-Mendoza EM. Scientific and academic journals in the Philippines: status and challenges. Sci Ed 2015;2:73-8. https://doi.org/10.6087/kcse.47

4. ACI Steering Committee. The journey for the development of the ACI [Internet]. [place unknown]: ACI Steering Committee; 2019 [cited 2019 Jun 20]. Available from: http:// www.asean-cites.org/index.php? $r=$ contents\%2Findex\&id $=7$

5. ACI Steering Committee. Why ACI [Internet]. [place unknown]: ACI Steering Committee; 2019 [cited 2019 Jun 20]. Available from: http://www.asean-cites.org/index. 
php? $r=$ contents\%2Findex\&id $=6$

6. ACI Steering Committee. Journal selection criteria [Internet]. [place unknown]: ACI Steering Committee; 2019 [cited 2019 Jun 20]. Available from: http://www.aseancites.org/index.php? $r=$ contents\%2Findex\&id $=10$

7. Sombatsompop N. Criterion for ASEAN Citation Index journal evaluations. Paper presented at: The fourth ASEAN Citation Index (ACI) Editor's Workshop; 2016 Dec 15; Bangkok, Thailand.

8. Scopus. Content policy and selection [Internet]. Amster- dam: Elsevier [cited 2019 Jun 20]. Available from: https:// www.elsevier.com/solutions/scopus/how-scopus-works/ content/content-policy-and-selection

9. Committee on Publication Ethics; Directory of Open Access Journals; Open Access Scholarly Publishers Association; World Association of Medical Editors. Principles of transparency and best practice in scholarly publishing, 3rd version [Internet]. [Place unknown]: Directory of Open Access Journals; 2018 [cited 2019 Jun 20]. Available from: https://doaj.org/bestpractice 